\title{
DNA Barcoding unveils skate (Chondrichthyes: Rajidae) species diversity in 'ray' products sold across Ireland and the UK
}

Skates are widely consumed across the globe, but many large species are subject to considerable concern regarding their conservation and management. Within Europe such issues have recently driven policy changes so that, for the first time, reports of skate landings now have to be made under species-specific names. Total allowable catches have also been established for many groups, which have been set to zero for a number of the most vulnerable species (e.g. Dipturus batis, Raja undulata and Rostoraja alba). Whilst accurate species identification has become an important issue for landings, the sale of skates is still usually made under a blanket term of "skate" or "ray". The matter of identifying species of skate is further complicated by their morphologically conservative nature and the fact that they are commercially valued for their wings. Thus, before sale their bodies are usually discarded (i.e. "winged”) and often skinned, making morphological identification impossible. For the first time, DNA barcoding (of the mitochondrial COI gene) was applied to samples of skate wings from retail outlets across the British Isles, providing insight into which species are sold for consumption. A total of 98 wing samples were analysed, revealing that six species were sold; blonde ray (Raja brachyura), spotted ray (Raja montagui), thornback ray (Raja clavata), cuckoo ray (Leucoraja naevus) small-eyed ray (Raja microocellata) and shagreen ray (Leucoraja fullonica). Statistical testing demonstrated that there were significant differences in the species sold in the distinct retail groups which suggests complex drivers behind the patterns of sale in skates The results also indicate that endangered species are not commonly being passed on to consumers. In addition, the practice of selling skate wings under ambiguous labels is highlighted as it makes it extremely difficult for consumers to exercise a right to avoid species of conservation concern. Interestingly, a single retailer chain labelled their wings as originating from three smaller-growing species (generally to be considered of lower conservation concern); of the six samples analysed from this company a third were mislabelled and originated from the thornback ray (a larger species that is currently undergoing population declines). 
1 Andrew Mark Griffiths, School of Environment and Life Sciences, University of

2 Salford, Greater Manchester M5 4WT, UK

3 Dana D. Miller, School of Biology \& Environmental Science, Science Education

4 and Research Centre - West, University College Dublin, Belfield, Dublin 4, Ireland

5 AND Fisheries Centre, University of British Columbia, 2204 Main Mall,

6 Vancouver, British Columbia, Canada V6T 1Z4

7 Aaron Egan, School of Biology \& Environmental Science, Science Education and

8 Research Centre - West, University College Dublin, Belfield, Dublin 4, Ireland

9 Jennifer Fox, School of Biology \& Environmental Science, Science Education and

10 Research Centre - West, University College Dublin, Belfield, Dublin 4, Ireland

11 Adam Greenfield, School of Environment and Life Sciences, University of Salford,

12 Greater Manchester M5 4WT, UK

13 Stefano Mariani, School of Environment and Life Sciences, University of Salford,

14 Greater Manchester M5 4WT, UK

15

16 Corresponding author; Andrew Mark Griffiths, e-mail -

17 andiff100@googlemail.com, tel - +44 7812051365

18

19

20 


\section{Introduction}

Skates (batoid elasmobranchs of the family Rajidae, but colloquially

23 referred to as rays) are consumed across the world with recent estimates of

24 global total catch reaching approximately 720,000 tonnes per annum (Seafish,

25 2013). Whilst skates are rarely specifically targeted by fisheries, they form a

26 significant by-catch and constitute an important commercial group for human

27 consumption. The group also contains many species that are potentially

28 vulnerable to even low levels of harvesting due to their large size, slow growth,

29 late maturity and low fecundity (Dulvy and Reynolds, 2002). This has famously

30 been demonstrated in the common skate species complex (Dipturus batis), which

31 was the first fish to become locally extinct in parts of its former range through a

32 clear link to commercial fishing (Brander, 1981). Of the 75 rajids assessed by the

33 International Union for the Conservation of Nature (IUCN) red list of threatened

34 species (excluding those defined as data deficient), 19 are listed as threatened

35 (IUCN, 2012). In response to skate declines, the European Union (EU) has now

36 established total allowable catches (TAC) for skates in most European waters,

37 and currently it is 'prohibited for EU vessels to fish for, to retain on board or to

38 land' three species; Raja undulata, Raja alba and the D. batis-complex (CEC, 39 2013).

40

41 Until recently, landings of different skate species were combined under a

42 single category, such that serious declines in one species could effectively be

43 masked by stable trends in more abundant groups (Dulvy et al., 2000). Therefore,

44 to more easily assess trends in abundance of individual species, a recent EU

45 Regulation (CEC, 2013) has been introduced to ensure that landings of many 
46 skates are recorded by species and not as an aggregated group. Identification

47 remains problematic as skates are a morphologically conservative group, making

48 the process of distinguishing between some species difficult. Furthermore,

49 similarly to shark finning, skates are only commercially valued for their large

50 pectoral fins (or 'wings'), so prior to sale their bodies are usually discarded (i.e.

51 "winged") and often skinned, making morphological identification impossible.

52 Molecular genetic techniques for species identification therefore represent the

53 only methods for distinguishing between different skates, allowing for the

54 protection of threatened species or populations, and also the recognition of

55 groups with different commercial values. Indeed, previous studies utilising

56 molecular approaches for species identification of skate species have proved

57 highly effective, often helping to uncover previously cryptic diversity (Martin Diaz

58 De Astarloa et al., 2008, Smith et al., 2008, Griffiths et al., 2010).

59

60

In recent years international efforts have been made to establish a

61 standardised reference DNA barcode of life database (BOLD;

62 www.barcodinglife.org; Ratnasingham and Hebert 2007), with the aim of

63 generating cytochrome-c oxidase I or COI gene sequences to facilitate the

64 identification of all animals. This includes a campaign to DNA barcode all fishes;

65 FISH-BOL (Ward, Hanner and Hebert, 2009). In fact, specific efforts have already

66 been made to collect validated barcode sequences for skates both within Europe

67 (Serra-Pereira et al., 2010), and globally (Ward et al. 2008, Coulson et al.2011,

68 Lago et al. 2012). These reference sequences have now facilitated numerous

69 molecular studies of species identification and mislabelling, which have helped

70 identify high levels of substitution in many commercial products (Marko et al., 
71 2004, Wong and Hanner, 2008, Cawthorn et al., 2012). Particular insights have 72 also been gained through applications of DNA barcoding to elasmobranch 73 products, which have demonstrated high levels of fraudulent substitutions in 74 sales of sharks (Barbuto, 2010), identified endangered species in confiscated 75 shark fins (Holmes and Steinke, 2009) and revealed the sale of endangered 76 sawfish as "shark" fillets in markets in Brazil (Palmeira et al., 2013).

77

Despite EU legislation regarding the correspondence of species/Latin 79 names for landings, skates are still generally sold under the broad title of ray or 80 skate wings (with skate wings typically originating from the larger fish). 81 Therefore, little remains known about exactly which species are passed on to 82 consumers. Beside the increasing number of studies reporting substantial levels 83 of seafood mislabelling (Logan et al. 2008, Miller and Mariani 2010), the 84 importance of guaranteeing informed consumer choice has also been highlighted 85 (Miller, Jessel and Mariani, 2012), which is particularly relevant to the sales of 86 skate. Moreover, in recent years several large supermarket chains have 87 consciously moved from stocking 'skate' to 'ray' wings, presumably reflecting a 88 desire to sell smaller species from more sustainable sources (Waitrose 2009). This 89 study represents the first intensive investigation into the patterns of the sale of 90 skate species in the North-east Atlantic, specifically the Republic of Ireland (ROI) 91 and the United Kingdom (UK), with a particular focus on a) whether those species 92 that are prohibited to land within the EU appear on sale, and b) if market 93 variations can be detected between different retail sectors and/or regions.

94

95 Materials \& Methods

PeerJ reviewing PDF | (v2013:04:411:1:0:NEW 18 Jul 2013) 
97 Sample Collection

98 Samples labelled as ray or skate wings were initially purchased from

99 fishmongers or fish counters within supermarkets and takeaway 'fish and chips' 100 shops from across Dublin (ROI). The retailers were also visited in two distinct 101 periods; January-February and October-November 2010. A total of 58 wings from 10210 fish mongers/counters and 9 takeaways were analysed (table 1 and 103 supplementary materials). In order to provide a wider view of patterns of skate 104 consumption, 40 additional fresh ray or skate wings were also collected between 105 October 2012 and March 2013 from around the UK; sampling was focused in the 106 south-west of England (i.e. counties of Devon and Cornwall), north-west England 107 (largely in Greater Manchester and Liverpool), Glasgow (Scotland), and Cardiff 108 (Wales). UK samples were limited to 'fresh' products as investigations of 109 takeaways in the UK cities failed to identify any that sold skate. Repeat sampling 110 from any single shop was kept to a minimum, although it was necessary in some 111 cases to increase the sample size (but efforts were generally made to sample on 112 different dates or from different sized wings; supplementary materials 1). 113 Therefore, between January 2010 and March 2013 a total 98 wings were 114 collected from 49 different retailers across the ROI and UK.

116 Molecular Analysis

117 Tissue samples were collected following Miller et al. (2010) and DNA 118 extractions were completed according to a modified chloroform extraction 119 procedure (Petit et al., 1999). DNA barcoding (specifically of COI gene) was 120 selected as the species identification tool (Hebert et al., 2003). Approximately 
121648 base pairs (bp) of the COI region were amplified by polymerase chain 122 reaction (PCR) using primers designed by Ward et al. (2005): FishF2 123 (5'-TCGACTAATCATAAAGATATCGGCAC-3') and FishR2

124 (5'-ACTTCAGGGTGACCGAAGAATCAGAA-3'). Reaction conditions following 125 Serra-Pereira et al. (2010) were utilized for all purchased skate samples. The PCR 126 products were sequenced by Macrogen Inc, Seoul, and Source Bioscience, 127 Nottingham, and the results were checked by eye in BIOEDIT version 7.1.11 (Hall 128 1999) for errors and ambiguous base calls. The sequences were then input into 129 the BOLD system using the species level barcode database to identify the species 130 of each sample and then cross-referenced using BLAST on GenBank (Basic Local 131 Alignment Search Tool, National Centre for Biotechnology Information, Bethesda, 132 Maryland; www.ncbi.nlm.nih.gov/). A 98\% similarity criterion was used as a 133 threshold above which identification of unknown samples was deemed reliable 134 (as analysis of barcode records suggests at divergence of greater than $2 \%$ it is 135 very likely that sequences belong to different species, Ward 2009). Any additional 136 matches within this $98 \%$ criterion are also reported in the supplementary 137 materials. However, in the case of the BOLD system only additional matches 138 within the Public Record Barcode database are described. This should help 139 ensure that the primary identification is made with a comprehensive database 140 that maximises the chance of finding a strong match, but any additional matches 141 are only made with the more closely regulated dataset, helping to reduce issues 142 associated with the misidentification of submitted records.

144 Data Analysis 
146 (Clarke \& Warwick, 2001), with each retailer representing an individual data point in the 147 ordination. The software was also used to conduct a non-parametric analysis of similarity 148 (ANOSIM) with 999 permutations, and to calculate the contribution of variables to similarity 149 (or similarity percentages; SIMPER). Both utilised the Bray-Curtis similarity measure during 150 calculation. Otherwise, the program defaults were utilised.

151

\section{Results \& Discussion}

153 DNA Barcoding

154 Good quality sequences were obtained for all 98 skate samples, these varied 155 in length between 494-646 bp (average length 617.9 bp). Searches on BOLD and 156 GenBank generally produced clear matches allowing for confident assignment of 157 species and there was good agreement between databases. In fact, all the 158 searches yielded matches that were within $98 \%$ similarity to database records, 159 with one exception (supplementary materials 1 ). In this case an $100 \%$ match on 160 BOLD was made, but no results within the $98 \%$ similarity criterion were located 161 in GenBank, so the BOLD identification was utilised Additionally, in 24 cases a 162 second close match (also with less than $2 \%$ divergence to the unknown samples) 163 was also identified. These additional matches originated from closely related 164 sister taxa, but in every case the species were not distributed around the British 165 Iles (they included; Raja maderensis that is restricted to Maderia and the Azores, 166 Raja polystigma that is restricted to the Mediterranean, Raja straeleni and 167 Leucoraja walacei that both have a primarily South African distribution). 168 Therefore, the additional matches were deemed unlikely to be the true source of 
169 the samples and the species with the highest degree of similarity from the BOLD

170

171

172

173

174

175 (Leucoraja fullonica).
177

178

179

180

181

182

183

184

185

186

187

188

189

190

191 temporally replicated samples collected in January/February and

192 October/November 2010 from Dublin was non-significant $(R=0.073, p=0.052)$.

193 As the result was close to the 95\% confidence interval, tests were also made 
194 between the temporal replicates of the fishmongers $(R=0.091, p=0.130)$ and 195 takeaways $(\mathrm{R}=0.017, \mathrm{p}=0.298)$ separately, which were also non-significant. In 196 contrast, the comparison between Dublin fishmongers and takeaways was highly 197 significant $(\mathrm{R}=0.182, \mathrm{p}=0.001)$, with the SIMPER results demonstrating 198 average dissimilarity of $69.89 \%$ between samples (with the highest contributions 199 originating from the blonde and spotted rays, each contributing about a third of 200 the total dissimilarity). Comparison of fishmongers in the ROI and the UK was 201 non-significant $(\mathrm{R}=-0.12, \mathrm{p}=0.995)$.

202

203

\section{Conservation Issues}

204

Across the study, no species with a vulnerable status on the redlist (IUCN, 205 2012), or an EU zero TAC, was identified. Given the severe declines in abundance 206 of these skate species, this may simply reflect the relatively modest sample 207 collection assembled here, but considerable efforts across the British Isles have 208 been made to emphasise the conservation status and TAC limits placed on many 209 skates (e.g. Seafish 2013). Therefore, the complete absence of species of critical 210 conservation concern may also reflect effective controls by the EU and efforts of

211 fishermen and stakeholders to reduce landings of these groups. Perhaps a more 212 stringent test of such action could be made in regions where threatened species 213 are more locally abundant: e.g. R. undulata remains relatively common around 214 the Channel Isles (Ellis, McCully, \& Brown 2012), and analyses focused on this 215 area could form a more rigorous test of effective landing controls. Interestingly, 216 the largest growing species identified ( $R$. brachyura) also occurred most 217 frequently in the study. Maybe more awareness should focus on $R$. brachyura as 218 size has been suggested as a good proxy for vulnerability to overexploitation 
219 (Dulvy and Reynolds 2002). R. brachyura R. clavata and L. fullonica that were 220 identified in the purchased wings are already included under the

221 'near-threatened' category in the IUCN redlist. $R$. brachyura is also listed under 222 the red category in the Marine Conservation Society's good fish guide (MCS 223 2013), which suggests it should not be so extensively consumed. Perhaps 224 guidelines on the maximum size of skate wings sold would increase consumer 225 confidence that the products originate from sustainable sources and reinforce 226 action to protect some of the vulnerable large growing species. This would 227 certainly simplify consumer choice, but could potentially overlook trading or 228 harvesting of juveniles from the large growing species that could go undetected 229 due to their small size.

230

231 Variation in Patterns of Sale

232 This study represents a relatively intensive effort to collect samples from 233 ray wings across multiple time-points, regions and countries, and goes beyond 234 many previous investigations of seafood and mislabelling that focused on a single 235 city, port or landing. Notwithstanding these efforts, it has resulted in a relatively 236 modest sample collection. In part this reflects the fact that ray wings were not 237 commonly available in some areas (particularly within the UK, where many 238 retailers were visited that did not stock them), but it also reflects a desire to 239 avoid high levels of repeat sampling from any one location or supermarket chain. 240 It is hoped this approach gives the samples analysed a high degree of 241 independence (not just repeatedly sampling from the same supply chains), 242 producing a truly comprehensive examination of the sale of skates. Therefore

243 despite the modest sample size, this study represents the first occasion that an PeerJ reviewing PDF | (v2013:04:411:1:0:NEW 18 Jul 2013) 
244 investigation of the patterns of sale of ray wings can be made between retailer

245 types, seasons and regions.

246

A highly significant difference was identified in species sold between

248 fishmongers and takeaways within Dublin. The additional level of processing in

249 takeaways provides greater opportunity for large wings originating from larger

250 species to be divided before sale. Conversely, wings from smaller growing species

251 may form more attractive sizes for sale in fishmongers. In recent years a number

252 of supermarkets have also made a move towards selling wings from smaller skate

253 species (Waitrose 2009), marketing them as sustainably sourced 'ray' wings. As

25428 of the ray wings sampled across the entire study in the fishmonger group

255 originated from supermarket fish counters, this may help explain the difference

256 in species sold. It is also interesting to note that whilst all the samples analysed

257 were labelled as "ray" or "skate" (and all the species identified belonged to the

258 Rajidae family, complying with broad expectations of the labels), one supermarket

259 chain went further and specified its wings originated from three smaller growing

260 species. In the six cases where wings were analysed from this chain two belonged

261 to $R$. clavata that was not included on the label, therefore, demonstrating a 33\%

262 level of mislabelling within this small subset of samples. Overall, the sale of

263 skates under ambiguous names remains a challenge to the consumers' ability to

264 exercise a right to choose those from less vulnerable groups.

265

266

A somewhat surprising result from the data analysis was the failure to

267 identify any significant difference in the patterns of species sold in the

268 January/February and October/November sample collections from Dublin. Many 
269 elasmobranch species are highly migratory, particularly with reference to specific 270 nursery areas, with marked seasonal movements between the North Sea and

271 Thames estuary for R. clavata having already been observed (Hunter et al. 2005). 272 Therefore, it may be expected that such seasonal movements would affect 273 capture vulnerability in commercial fisheries, and hence patterns of availability to 274 consumers. One explanation for this result is that retailers will freeze stocks of 275 fish to ensure a steady supply. In the case of skates, previous work suggest this is 276 not common, even within takeaway shops, as they wings do not freeze well so 277 supply was dependent on local fisheries (Miller and Mariani 2013). However, 278 much remains unknown about the exact provenance of samples sold, behaviour of 279 fisherman and even the movements of skate species (Ellis et al. 2005), such that 280 interpreting patterns of sale of skates remains difficult.

281

The same problems for interpretation occur when comparing sales in the 283 patterns of skate species sold were observed between the different countries 284 (ROI and UK), which were also non-significant. Perhaps this reflects the fact that 285 the sale of ray wings in both countries exploits similar species and stocks of 286 skates. Although in this case the comparison is also confounded by the fact that 287 sample collection was conducted approximately two years apart. The only other 288 study to utilise genetic methods of species identification on skate products was 289 recently conducted by Lago et al. (2012) in Spain. The 10 samples of whole or 290 winged fresh skate analysed there originated not only from species found around 291 Spain, but included groups restricted to other areas of Europe and even South 292 America. This suggests patterns of sale could vary dramatically between 
293 countries or regions and they will not simply reflect levels of abundance in local

294 fisheries.

295

296 Conclusions

297

This study represents the first intensive effort to investigate patterns in the

298 sale of skate wings. The results show that no species with a vulnerable status on

299 the redlist (IUCN, 2012), or with prohibited landings in the EU, appear to

300 contribute to the market. Given the low abundance of many of these species

301 further investigations may be required to accurately assess whether these groups

302 may reach points of sale anywhere in Europe. Investigations at the point of

303 landing, and throughout the supply chain, would also provide interesting insights

304 into accuracy of identification and reveal if any species are landed, but

305 withdrawn, before reaching retailers. The results also demonstrate significant

306 differences between the retailers (fishmonger and takeaway) included in the

307 study. Understanding why fishmongers also tended to sell smaller-growing

308 species is challenging, but may relate to a desire to supply less vulnerable

309 groups. This study also highlights that the use of ambiguous and amalgamated

310 sales terms makes it extremely difficult for consumers to exercise a right to

311 choose species of lesser conservation concern. Interestingly, analysis of six wings

312 from the only retailer to label its ray wings as originating from three smaller

313 growing species showed two (33\%) actually originated from R. clavata, a larger

314 species with a decreasing population trend that is listed as near threatened on

315 the IUCN redlist (IUCN, 2012).

316

\section{Acknowledgements}

PeerJ reviewing PDF | (v2013:04:411:1:0:NEW 18 Jul 2013) 
318 Carlotta Sacchi, Jennifer Coughlan and Belgees Boufana are gratefully 319 acknowledged for their technical support during this project. Thanks are also due 320 to Phil Cannon, Mary Lane, Richard Cooper and Sam Cooper for their aid in 321 supporting sample collection.

322

\section{Funding Statement}

324 This work was jointly funded by the European Union INTERREG Atlantic Area 325 Program ('LabelFish', project 2011-1/163) and the Irish Research Council (IRC). 326 Additional support also originated from University College Dublin and the 327 University of Salford.

328

329 References

330 Brander K. 1981. Disappearance of common skate Raja batis from Irish Sea.

331 Nature, 290: 48-49.

332 Barbuto, M., Galimberti, A., Ferri, E., Labra, M., Malandra, R., Galli, P., \&

333 Casiraghi, M. (2010). DNA barcoding reveals fraudulent substitutions in shark 334 seafood products: The Italian case of "palombo"(Mustelus spp.). Food research 335 international, 43(1), 376-381.

337 Cawthorn, D. M., Steinman, H. A., \& Witthuhn, R. C. (2012). DNA barcoding

338 reveals a high incidence of fish species misrepresentation and substitution on the 339 South African market. Food Research International, 46(1), 30-40. 
341 CEC 2013. COUNCIL REGULATION (EU) No 39/2013 of 21 January 2013 fixing for 2013

342 the fishing opportunities available in EU waters and, to EU vessels, in certain non- EU 343 waters for certain fish stocks and groups of fish stocks which are subject to international 344 negotiations or agreements. Official Journal of the European Communities L23: 1-53.

345 Available at http://eur-lex.europa.eu/LexUriServ/LexUriServ.do? 346 uri=OJ:L:2013:023:0001:0053:EN:PDF

348 Clarke KR \& Warwick,RM. 2001 Change in marine communities: an approach to 349 statistical analysis and interpretation, 2nd edn. Plymouth, UK: Plymouth Marine 350 Laboratory.

351

352 Coulson, M. W., Denti, D., Van Guelpen, L., Miri, C., Kenchington, E., \& Bentzen, 353 P. (2011). DNA barcoding of Canada's skates. Molecular Ecology Resources, 354 11(6), 968-978.

355

356

357 Dulvy NK, Metcalfe JD, Glanville J, Pawson MG and Reynolds JD. 2000. Fishery

358 stability, local extinctions, and shifts in community structure in skates.

359 Conservation Biology, 14: 283-293.

360

361 Dulvy NK and Reynolds JD. 2002. Predicting extinction vulnerability in skates.

362 Conservation Biology, 16: 440-450.

363

364 Ellis JR, Cruz-Martínez A, Rackham BD and Rogers SI. 2005. The Distribution of

365 Chondrichthyan Fishes Around the British Isles and Implications for

366 Conservation. Journal of Northwest Atlantic Fishery Science, 35: 195-213. PeerJ reviewing PDF | (v2013:04:411:1:0:NEW 18 Jul 2013) 
368 Ellis J , McCully SR and Brown MJ. 2012. An overview of the biology and status of 369 undulate ray Raja undulata in the north-east Atlantic Ocean. Journal of Fish 370 Biology, 80: 1057-74.

371 Griffiths AM, Sims DW, Cotterell SP, El Nagar A, Ellis JR, Lynghammar A, 372 McHugh M, Neat FC, Pade NG, Queiroz N, Serra-Pereira B, Rapp T, Wearmouth 373 VJ \& Genner MJ. 2010. Molecular markers reveal spatially segregated cryptic 374 species in a critically endangered fish, the common skate (Dipturus batis).

375 Proceedings of the Royal Society London B: 277 1497-1503

376

377 Hall TA. 1999. Nucleic Acids Symposium Series, 41: 95-98.

378

379 Hebert PDN, Cywinska A, Ball SL and deWaard JR. 2003. Biological

380 identifications through DNA barcodes. Proceedings of the Royal Society London 381 B, 270: 313-21.

382

383 Holmes, B. H., D. Steinke, et al. (2009). "Identification of shark and ray fins using 384 DNA barcoding." Fisheries Research 95: 280-288.

385 Hunter E. Buckley AA,. Stewart C and Metcalfe JD. 2005. Repeated seasonal migration by 386 a thornback ray in the southern North Sea. Journal of the Marine Biological 387 Association, 85: 1199-1200 388

389 IUCN. 2012. The IUCN Red List of Threatened Species. Version 2012.2.

$390<$ http://www.iucnredlist.org > . Downloaded on 04/03/13. 391 
392

393

394

395

396 Logan CA, Alter SE, Haupt AJ, Tomalty K and Palumbi SR. 2008. An impediment

397 to consumer choice: overfished species are sold as Pacific red snapper. Biological

398 Conservation 141: 1591-1599.

399

400 Marko, P. B., Lee, S. C., Rice, A. M., Gramling, J. M., Fitzhenry, T. M., McAlister, J.

401 S., Harper, J. R. \& Moran, A. L. (2004). Fisheries: mislabelling of a depleted reef 402 fish. Nature, 430(6997), 309-310.

403

404 Martin Diaz De Astarloa, J., Mabragana, E., Hanner, R., \& Figueroa, D. E. (2008). 405 Morphological and molecular evidence for a new species of longnose skate 406 (Rajiformes: Rajidae: Dipturus) from Argentinean waters based on DNA 407 barcoding. Zootaxa, (1921), 35-46.

408

409

410 411

412 Miller D, Jessel A and Mariani S. 2012. Seafood mislabelling: comparisons of two

413 western European case studies assist in defining influencing factors, mechanisms

414 and motives. Fish and Fisheries, 13, 345-358

415 
416 Miller DD and Mariani S. 2010. Smoke, mirrors, and mislabeled cod: poor

417 transparency in the European seafood industry. Frontiers in Ecology and the

418 Environment, 8: 517-521.

419

420 Miller DD and Mariani S. (2013) Irish fish, Irish people: roles and responsibilities

421 for an emptying ocean - Environment, Development and Sustainability (2013) 15:

$422 \quad 529-546$

423

424 Melo Palmeira, C. A., da Silva Rodrigues-Filho, L. F., de Luna Sales, J. B., 425 Vallinoto, M., Schneider, H., \& Sampaio, I. (2013). Commercialization of a 426 critically endangered species (large tooth sawfish, $<\mathrm{i}>$ pristis perotteti $</ \mathrm{i}>$ ) in 427 fish markets of northern brazil: authenticity by dna analysis. Food Control.

428

429

430 Petit E, Excoffier L and Mayer F. 1999. No evidence of bottleneck in the

431 postglacial recolonization of Europe by the noctule bat (Nyctalus noctula).

432 Evolution 53: 1247-58.

433

434 Ratnasingham S, and Hebert PDN. 2007. BOLD: the barcode of life data system.

435 Molecular Ecology Notes, 7: 355-64.

436

437 Serra-Pereira B. Moura T. Griffiths AM. Gordo LS and Figueiredo I. 2010.

438 Molecular barcoding of skates (Chondrichthyes: Rajidae) from the southern

439 Northeast Atlantic. Zoologica Scripta: 40: 76-84.

440 
441 Seafish. 2013. Responsible sourcing guide: skates and rays.

442

443 Smith PJ. Steinke D. Mcveagh SM. Stewart AL. Struthers CD and Roberts CD.

4442008 Molecular analysis of Southern Ocean skates (Bathyraja) reveals a new

445 species of Antarctic skate. Journal of Fish Biology. 73, 1170-1182.

446

447

448

449 Waitrose 2009. The Very Useful Guide to Fish (downloaded 16/04/2013 and

450 available online from;

451 http://www.waitrose.com/content/dam/waitrose/pdf/inspiration/foodissuesandpoli

452 cies/2009\%20Guide\%20to\%20fish_lo\%20res.pdf)

453

454 Ward, R. D., Zemlak, T. S., Innes, B. H., Last, P. R., \& Hebert, P. D. (2005). DNA

455 barcoding Australia's fish species. Philosophical Transactions of the Royal

456 Society B: Biological Sciences, 360(1462), 1847-1857.

457

458 Ward, R. D., Hanner, R., \& Hebert, P. D. (2009). The campaign to DNA barcode all

459 fishes, FISH-BOL. Journal of Fish Biology, 74(2), 329-356.

460

461 Ward, R. D., Holmes, B. H., White, W. T., \& Last, P. R. (2008). DNA barcoding

462 Australasian chondrichthyans: results and potential uses in conservation. Marine

463 and Freshwater Research, 59(1), 57-71.

464

PeerJ reviewing PDF | (v2013:04:411:1:0:NEW 18 Jul 2013) 
465 Ward, R. D. (2009). DNA barcode divergence among species and genera of birds 466 and fishes. Molecular Ecology Resources, 9(4), 1077-1085.

467

468 Wong, E. H. K., \& Hanner, R. H. (2008). DNA barcoding detects market

469 substitution in North American seafood. Food Research International, 41(8), $470 \quad 828-837$.

471 


\section{Table $\mathbf{1}_{\text {(on next page) }}$}

Table 1. Details of ray wing sampling, summarising the numbers of retailers, number of samples and dates of collection at each location. Further information is given in the supplementary materials 1 . 
Table 1. Details of ray wing sampling, summarising the numbers of retailers, number of samples and dates of collection at each location. Further information is given in the supplementary materials 1.

\begin{tabular}{lllrrl}
\hline Location & Country & Retailer & No. Retailers & No. samples & Date \\
\hline Dublin & ROI & Monger & 10 & 18 & Jan 2010 - Feb 2010 \\
Dublin & ROI & Take-away & 9 & 16 & Jan 2010 - Feb 2010 \\
Dublin & ROI & Monger & 9 & 13 & Oct 2010 - Nov 2010 \\
Dublin & ROI & Take-away & 8 & 11 & Oct 2010 - Nov 2010 \\
NW & UK & Monger & 9 & 11 & Nov 2012 - Feb 2013 \\
England & & & & & \\
SW & UK & Monger & 11 & 11 & Oct 2012 - Mar 2013 \\
England & & & & & \\
Glasgow & UK & Monger & 3 & 9 & Jan 2013 \\
Cardiff & UK & Monger & 7 & 9 & Jan 2013 \\
\hline
\end{tabular}




\section{Table 2 (on next page)}

Table 2. Frequency of the skate species identified in each of the sample collections, across the 98 samples analysed 
Table 2. Frequency of the skate species identified in each of the sample collections, across the 98 samples analysed

\begin{tabular}{|c|c|c|c|c|c|c|c|c|c|}
\hline $\begin{array}{l}\text { Locatio } \\
\text { n }\end{array}$ & $\begin{array}{l}\text { Countr } \\
\mathrm{y}\end{array}$ & Retailer & Date & Thornback & Blonde & Spotted & Small-eyed & Cuckoo & Shagreen \\
\hline Dublin & ROI & Monger & $\begin{array}{l}\text { Jan } \\
2010-F e b \\
2010\end{array}$ & 5 & 3 & 9 & 0 & 1 & 0 \\
\hline Dublin & ROI & Take-away & $\begin{array}{l}\text { Jan } \\
2010-F e b \\
2010\end{array}$ & 6 & 8 & 1 & 1 & 0 & 0 \\
\hline Dublin & ROI & Monger & $\begin{array}{l}\text { Oct } \\
2010-\text { Nov } \\
2012\end{array}$ & 1 & 5 & 5 & 0 & 2 & 0 \\
\hline Dublin & ROI & Take-away & $\begin{array}{l}\text { Oct } \\
2010-\text { Nov } \\
2012\end{array}$ & 2 & 9 & 0 & 0 & 0 & 0 \\
\hline \multirow[t]{2}{*}{ Various } & UK & Monger & $\begin{array}{l}\text { Oct } \\
2012-M a r \\
2013\end{array}$ & 5 & 6 & 13 & 4 & 11 & 1 \\
\hline & & & TOTAL & 19 & 31 & 28 & 5 & 14 & 1 \\
\hline
\end{tabular}




\section{Figure 1}

Figure 1. Principal components analysis of retailers based on species of skates sold (principal component 1 explains $40.2 \%$ and principal component 2 explains $28.4 \%$ of the observed variation).

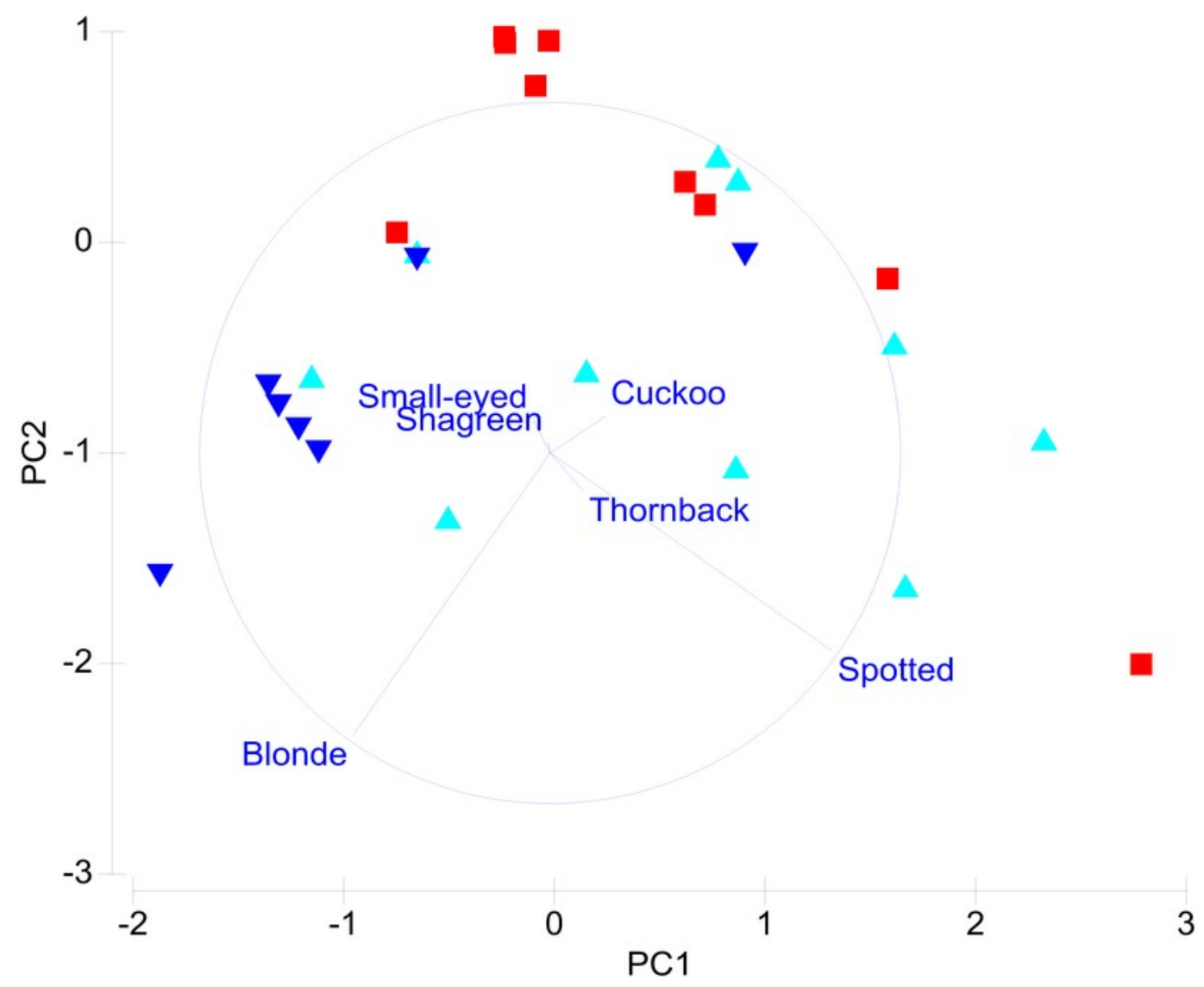

Country \& Retailer

$\triangle \mathrm{ROI}$ Monger

$\boldsymbol{\nabla}$ ROI Take-away

- UK Monger

PC1 